\title{
Electrolyte-Plasma Strengthening of Surface Layers of Aluminum Alloy
}

\author{
Kuat K. Kombayev*a and Liudmila I. Kveglis ${ }^{\mathrm{b}}$ \\ ${ }^{a}$ D. Serikbayev East Kazakhstan state technical university \\ East Kazakhstan region Ust-Kamenogorsk \\ 69 A.K. Protozanov Str., Ust-Kamenogorsk, 070004, Kazakhstan \\ ${ }^{b}$ Siberian Federal University \\ 79 Svobodny, Krasnoyarsk, 660041, Russia, 79
}

Received 19.02.2018, received in revised form 27.03.2018, accepted 16.04.2018

This article presents the results of studies of the effect of electrolyte-plasma treatment on the structural-phase transformation of aluminum alloy samples. The discharge was ignited from a constant current source. When the voltage is turned on, ionization and boiling of the electrolyte take place. When a bubble boiling occurs around the active electrode, large current pulsations are observed. Due to the formation of the gas-vapor jacket and the passage of electric current through it, a low-temperature plasma is formed which has a characteristic blue color of the glow of the shell around the part. On the surface of the product, an electric microarc plasma is excited, in which heat is generated from the intense heating of the workpiece. After microarc oxidation, a microstructure of quenching and artificial aging in the electrolyte flow is observed on the sample surface. As a result of quenching in the electrolyte stream, the solid copper solution in aluminum and the fine fine inclusions dissolve from the temperature of the microplasma, the phases oxidizing form aluminum corundum. X-ray diffraction analysis of samples after electrolyteplasma treatment revealed an increase in intensity and broadening of the diffraction lines relative to the initial state, which indicates the residual stress of the surface, which in the process of operation provides an increase in wear resistance of the part. The average microhardness, after electrolytic-plasma treatment, is $746 \mathrm{mpa}$, which is approximately 2.5 times higher than that of the starting material.

Keywords: aluminum, electrolyte-plasma processing, micro arc oxidation, microstructure.

Citation: Kombayev K.K., Kveglis L.I. Electrolyte-plasma strengthening of surface layers of aluminum alloy, J. Sib. Fed. Univ. Eng. technol., 2018, 11(4), 461-472. DOI: 10.17516/1999-494X-0069.

(C) Siberian Federal University. All rights reserved

* Corresponding author E-mail address: kombaev82@mail.ru 


\title{
Электролитно-плазменное упрочнение поверхностных слоев алюминиевого сплава
}

\author{
К.К. Комбаев ${ }^{\text {a }}$, Л.И. Квеглис \\ ${ }^{a}$ Восточно-Казахстанский государственный \\ технический университет им. Д. Серикбаева, \\ Казахстан, 070004, Усть-Каменогорск, ул. Протозанова А.К., 69 \\ ${ }^{6}$ Сибирский федеральный университет \\ Россия, 660041, Красноярск, пр. Свободньй, 79
}

\begin{abstract}
В данной статье приведены результаты исследований влияния электролитно-плазменной обработки на структурно-фазовое превращуение образияов алюминиевого сплава. Разряд зажигался от источника постоянного тока. При включении напряжения происходит ионизация и кипение электролита. При возникновении пузырькового кипения вокруг активного электрода наблюдаются большие пульсации силь тока. Вследствие образования газопаровой рубашки и прохождения через нее электрического тока образуется низкотемпературная плазма, которая имеет характерный голубой иввет свечения оболочки вокруг детали. На поверхности изделия возбуждается электрическая микродуговая плазма, в которой от тепловыделения происходит интенсивный разогрев заготовки. После микродугового оксидирования на поверхности образца наблюдается микроструктура закалки и искусственного старения в потоке электролита. В результате закалки в потоке электролита твердый $\alpha$-раствор меди в алюминии и точечные мелкодисперсные включения растворяются от температуры микроплазмы, фазы, окисляясь, образуют корунд алюминия. Рентгеноструктурный анализ образиов после электролитно-плазменной обработки выявил увеличение интенсивности и уширение дифракционных линий относительно исходного состояния, что свидетельствует об остаточном напряжении поверхности, которая в процессе эксплуатации обеспечивает повышение износостойкости детали. Средняя микротвердость после электролитноплазменной обработки составляет 746 МПа, что примерно в 2,5 раза выше, чем у исходного материала.
\end{abstract}

Ключевые слова: алюминий, электролитно-плазменная обработка, микродуговое оксидирование, микроструктура.

\section{Введение}

Как известно, для упрочнения алюминиевых сплавов применяют закалку. Закалка заключается в нагреве сплавов до температуры, при которой избыточные интерметаллидные фазы полностью или большей частью растворяются в алюминии. Выдержка при этой температуре и быстром охлаждении до нормальных температур позволяет получить перенасыщенный твердый раствор [1]. Температуру нагрева под закалку выбирают в зависимости от природы сплава, удовлетворяющего механические свойства, предъявляемые к детали. Температура закалки сплавов системы $\mathrm{Al}-\mathrm{Cu}$ (рис. 1) определяется линией абс, проходящей выше линии предельной растворимости для сплавов, содержащих меньше 5,7 \% $\mathrm{Cu}$, и ниже эвтектической линии $\left(548^{\circ} \mathrm{C}\right)$ для сплавов, содержащих большее количество меди [2]. Более высокие температуры вызывают пережог (оплавление по границам зерен), что приводит к образованию трещин, снижению сопротивления коррозии, механических свойств и сопротивления хрупкому разрушению. 


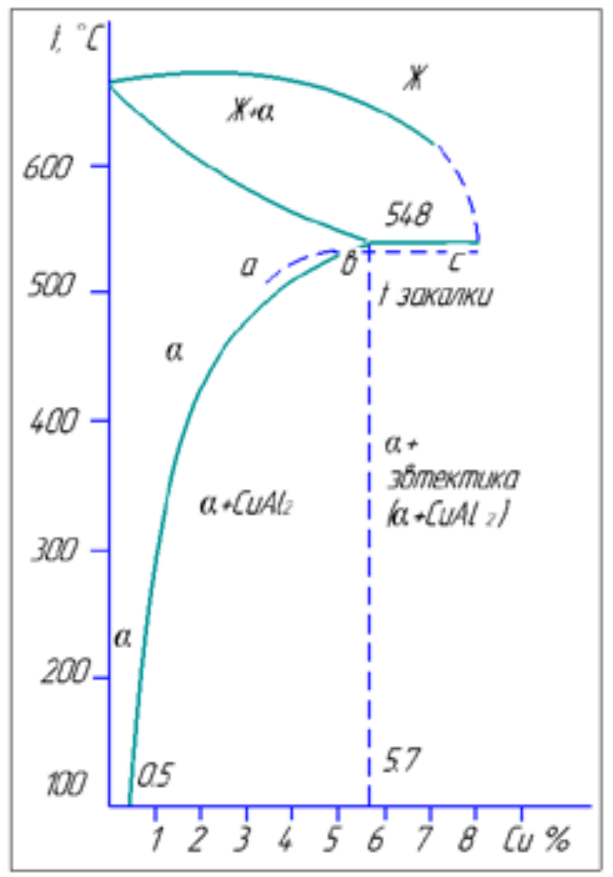

Рис. 1. Диаграмма состояния Al-Cu: штриховая линия - температура закалки

Fig. 1. The phase diagram of Al-Cu: dashed line is quenching temperature

После закалки следует старение, при котором сплав выдерживают при нормальной температуре несколько суток (естественное старение) или в течение 10-24 ч при повышенной температуре $150-200{ }^{\circ} \mathrm{C}$ (искусственное старение) [3].

Однако после закалки со старением поверхность окисляется, требует механической обработки, и получаемые покрытия не обеспечивают высокой износостойкости восстановленной поверхности.

\section{Методика проведения исследований}

Микроплазменная обработка применяется для весьма узкого круга материалов и в подавляющем большинстве направлена на получение прочного и износостойкого оксидного слоя на поверхности анода из алюминия и его сплавов [4]. Между тем потенциал этого метода еще не раскрыт, что связано с малой изученностью закономерностей формирования микроплазменных разрядов на поверхности анода и катода в различных электролитах и их влияния на структуру и свойства поверхности электродов. Для разработки технологии нанесения различных покрытий на поверхность детали при помощи микроплазменных разрядов в электролитах требуется изучить закономерности их формирования и воздействия на поверхность катода. Известно альтернативное устройство для микродугового оксидирования (МДО) колодцев корпуса шестеренного насоса из сплава алюминия [5]. Наиболее сильное структурное упрочнение алюминиевых сплавов проявляется при микродуговом оксидировании.

Для исследования микродугового оксидирования образцы размером $10 \times 10 \times 20$ мм (рис. 2) вырезали из сплава алюминия АЛ3 ГОСТ2685-75 алмазным диском толщиной в 1 мм, который

$$
-463-
$$


погружен в охлаждающую жидкость. При малых оборотах резания $\mathrm{n}=350$ об/мин и низкой нагрузке $\mathrm{m}=250$ г образец не испытывает термической деформации [6].

Экспериментальные исследования и механические испытания проводили в Региональной университетской лаборатории инженерного профиля «ІРГЕТАС» ВКГТУ им. Д. Серикбаева (г. Усть-Каменогорск) и в научно-технологическом парке «Лаборатории инженерного профиля» КазНТУ им. К.И. Сатпаева (г. Алматы) [7]. Элементный состав алюминиевого образца исследовали на растровом электронном микроскопе JSM-6390LV фирмы JEOL (Япония) с приставкой энергодисперсионного микроанализа INCAEnergy фирмы «OXFORD Instruments» [8]. Определяемые элементы - от бора до урана. Качественный и количественный фазовый анализ структуры образцов алюминиевого сплава проводили на рентгеновском дифрактометре ДРОН-3 в фильтрованном излучении медного анода, также «X'Pert PRO» фирмы «PANanalytical», с применением $\mathrm{Cu}-K \alpha$-излучения [9].

Разряд зажигался от источника постоянного тока. На рис. $3 a$ изображена схема источника постоянного тока, который состоит из кнопочного поста, пускателя, диодного моста, дросселя, автомата, амперметра, вольтметра и других электроприборов. Катод - образец из алюминия (АЛ3: 1,5-3,0 Cu; 0,35-0,6 Mg; 4,5-5,5 Si; 0,6-0,9 Mn), погружен на глубину 4-6 мм в электролит $10 \%$-ный водный раствор $\mathrm{Na}_{2} \mathrm{CO}_{3}[10]$.

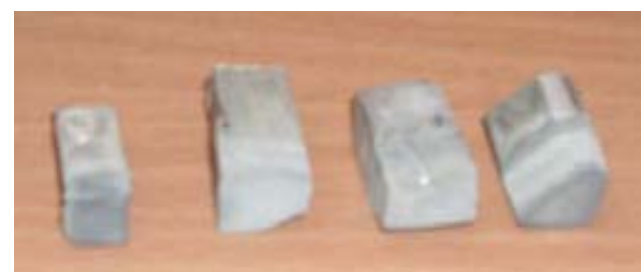

Рис. 2. Образцы для микродугового оксидирования

Fig. 2. Pieces for micro arc oxidation

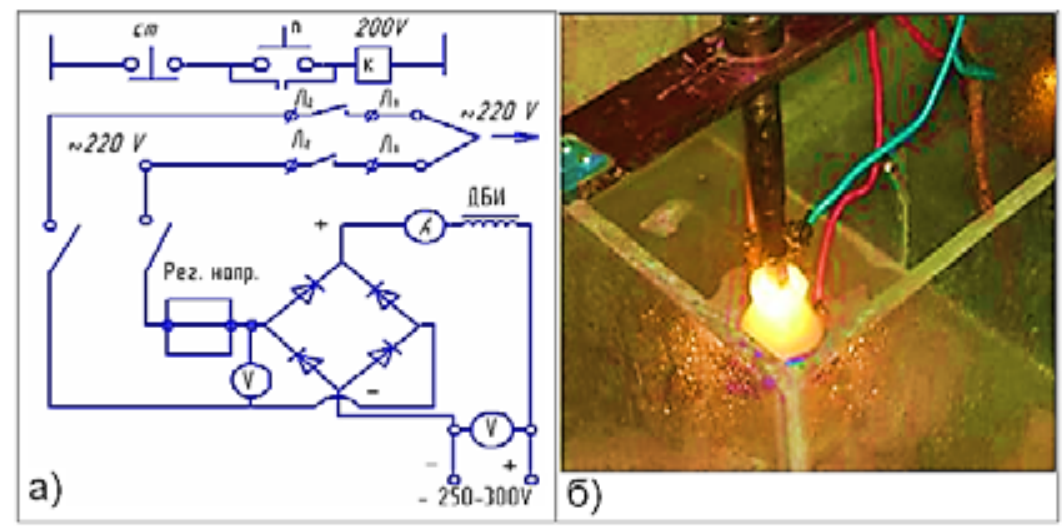

Рис. 3. Схема источника постоянного тока для микродугового оксидирования алюминиевых сплавов: а) электросхема источника постоянного тока, б) микродуговое оксидирование алюминия

Fig. 3. Scheme of a constant current source for micro arc oxidation of aluminum alloys: a) the electro scheme of constant current source, б) micro arc aluminum oxidation 
При включении напряжения на поверхности изделия возбуждается электрическая микродуга (рис. 3б), в которой от тепловыделения происходит интенсивный разогрев заготовки. Анод, имеющий форму диска диаметром 50 мм, толщиной 2 мм, с просверленными отверстиями Ø4 мм, изготовлен из нержавеющей стали 12Х18Н10Т.

Необходимо отметить тот факт, что качество поверхностного слоя, получаемого при микродуговом оксидировании, в значительной степени зависит от режимов процесса. От них зависит мощность искровых разрядов и, соответственно, энергия воздействия на упрочняемую поверхность. При плавном увеличении приложенного постоянного напряжения происходит электролиз соли, при этом, согласно закону Ома, растет и ток (участок 0 - А, рис. 4). Для данного участка характерно пропорциональное увеличение силы тока при увеличении напряжения. При этом увеличивается и температура электролита, что является следствием прохождения тока через электролит [11].

При достижении определенного значения напряжения (100-180 В) на поверхности катода - детали начинает вскипать электролит, происходит активное выделение пузырьков у поверхности (пузырьковое кипение). При пузырьковом кипении температура детали близка к температуре кипения воды. При возникновении пузырькового кипения вокруг активного электрода наблюдаются большие пульсации силы тока. Их амплитуда значительно уменьшается при разогреве детали свыше $470{ }^{\circ} \mathrm{C}$ [12]. При дальнейшем повышении выпрямленного напряжения появляется пленочное кипение (точка А, рис. 4), для которого характерно исчезновение пузырькового кипения и резкое падение силы тока вследствие того, что образующаяся газопаровая оболочка имеет большее электрическое сопротивление, чем жидкий электролит (участок A - B, рис. 4). Поскольку газопаровая рубашка является менее электропроводной, то основное падение напряжения происходит именно в этой зоне, где и выделяется большее количество тепла. Вследствие образования газопаровой рубашки и прохождения через нее электрического тока образуется низкотемпературная плазма, которая имеет характерный голубой цвет свечения оболочки вокруг детали. Чем

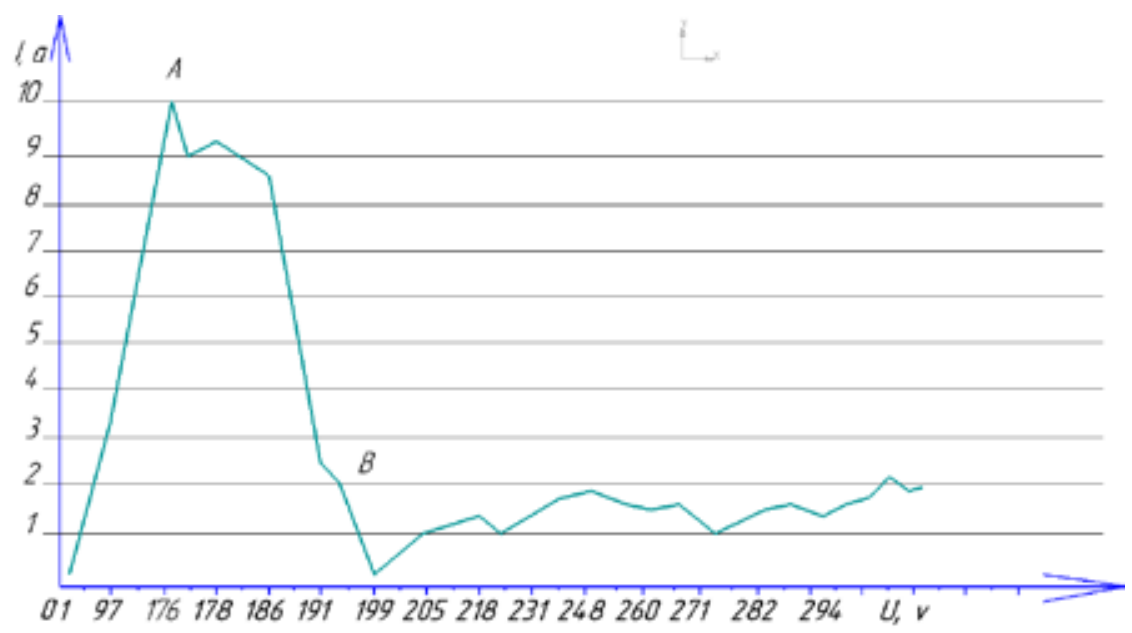

Рис. 4. Вольтамперная характеристика процесса электролитно-плазменной обработки

Fig. 4. Voltage-current characteristic of the electrolytum-plasma treatment

$$
-465-
$$


ярче голубой цвет горения плазмы, тем больше в ней содержится ионов, в том числе ионовмодификаторов. При дальнейшем увеличении напряжения наблюдается образование аномального разряда [13].

\section{Результаты исследований и их обсуждение}

Экспериментально установили оптимальные режимы микродугового оксидирования алюминия: напряжение $\mathrm{U}=200 \mathrm{~B}$, сила тока $\mathrm{I}=10 \mathrm{~A}$, время нагрева $\mathrm{t}=2 \mathrm{c}$, время закалки в потоке электролита $\mathrm{t}=24 \mathrm{c}$, общее количество циклов $\mathrm{n}=15$ [14]. Предварительно установили зависимость температуры нагрева от времени нагрева, охлаждения и напряжения, которое выражено формулой:

$$
\mathrm{T}=4.5 \mathrm{xt}^{2}{ }_{\text {наг. }}+4.8 \mathrm{xU}-18 \mathrm{xt}_{\text {охл. }} \text {, }
$$

где $\mathrm{T}$ - температура нагрева образца; $\mathrm{t}_{\text {наг. }}$ - время нагрева; $\mathrm{t}_{\text {охл. }}$ - время охлаждения в потоке электролита; U - напряжение источника питания.

Микродуга возникает между катодом и жидким электролитом [15]. Особое влияние на структурные превращения оказывает периодическое повышение температуры при подключе-

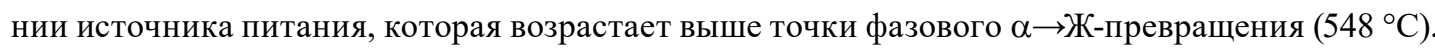
После отключения источника питания микродуга гаснет, что обеспечивает доступ электролита к разогретому сплаву и его быстрое охлаждение (закалка).

В структуре алюминиевого сплава в равновесном состоянии присутствуют зерна $\alpha$-твердого раствора (рис. $5 a$ ), в состав которого входят медь, марганец и магний, дисперсные включения $\mathrm{Mg}_{2} \mathrm{Si}$.

После микродугового оксидирования наблюдается микроструктура закалки и искусственного старения в потоке электролита (рис. 5б). В результате закалки твердый $\alpha$-раствор меди в алюминии и точечные мелкодисперсные включения растворяются от температуры микроплазмы, эти фазы, окисляясь, образуют корунд алюминия. Результаты элементного анализа после
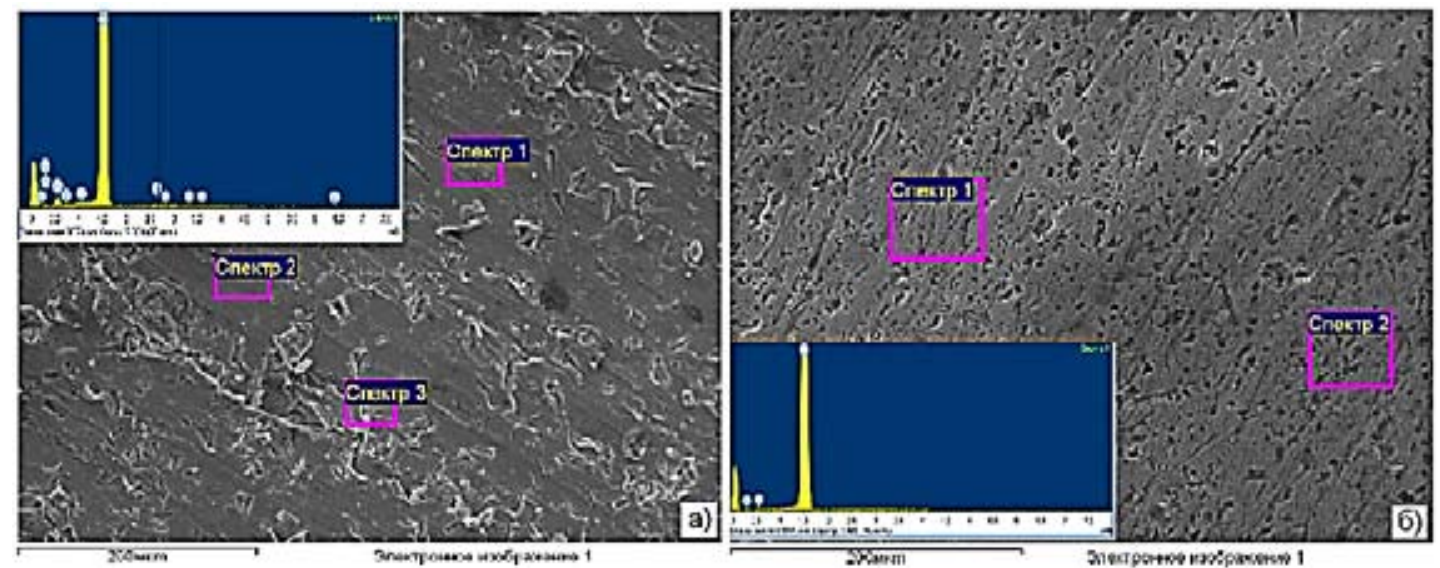

Рис. 5. Микроструктура алюминиевого сплава АЛ3: а) в исходном состоянии, б) после микродугового оксидирования

Fig. 5. The microstructure of aluminum alloy AL3: a) in the initial state, б) after the micro arc oxidation

$$
-466-
$$


микродугового оксидирования (табл. 1) свидетельствуют о появлении кислорода и включении соответствующих элементов упрочняемому сплаву алюминия.

Включения выделились из твердого $\alpha$-раствора в процессе искусственного старения. После старения поверхностный слой алюминия оксидируется. Элементы, выделяясь в дисперсной форме, упрочняют сплав. Могут быть обнаружены частицы $\mathrm{CuAl}_{2}$ и частицы магния [16]. Для выявления структурно-фазовых превращений алюминия в результате термического воздействия микродугового оксидирования провели рентгеноструктурный анализ [17]. Рентгеноструктурный анализ образцов алюминия в исходном состоянии поставки и после микродугового оксидирования (рис. 5) выявил наличие линий $\alpha$-фазы на основе Al.

После микродугового оксидирования наблюдается увеличение интенсивности и уширение дифракционных линий (рис. 6б) относительно исходного состояния (рис. 6a), что свидетельствует об остаточном напряжении поверхности, которая в процессе эксплуатации обеспечивает повышение качества детали.

Для определения фазового состава образца алюминиевого сплава, обработанного микродуговым оксидированием, осуществили компьютерную статистическую обработку результатов [18]. Рентгенофазовый анализ образцов показал наличие фаз оксида алюминия. Значения межплоскостных расстояний свидетельствуют, что угловые положения дифракционных линий образцов совпадают не полностью, а их интенсивности отличаются значительно (табл. 2).

Таблица 1. Элементный состав алюминия после МДО (к рис. 5б)

Table 1. Elemental composition of aluminum after MDO

\begin{tabular}{|c|c|c|c|c|c|c|}
\hline Спектр & $\mathbf{O}$ & $\mathrm{Na}$ & $\mathrm{A} 1$ & $\mathrm{Si}$ & $\mathrm{Cu}$ & Итог \\
\hline Спектр 1 & $\mathbf{2 . 5 8}$ & - & 97.42 & - & - & 100.00 \\
\hline Спектр 2 & $\mathbf{4 . 9 5}$ & 0.32 & 93.49 & 0.76 & 0.48 & 100.00 \\
\hline
\end{tabular}

(все результаты в весовых \%).
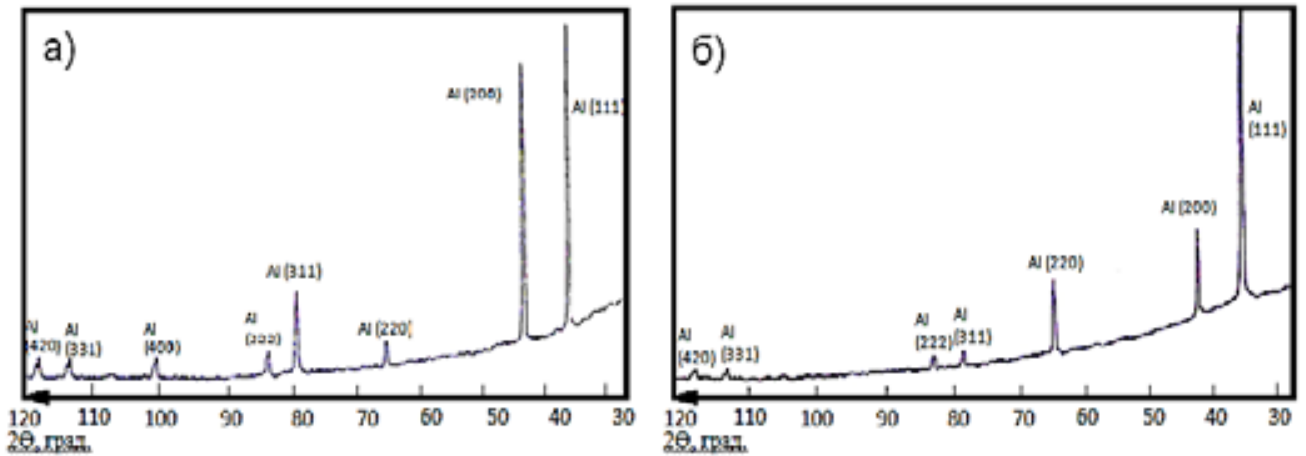

Рис. 6. Рентгеновская дифрактограмма алюминиевого сплава: а) - в исходном состоянии, б) - после микродугового оксидирования

Fig. 6. X-ray diffraction pattern of an aluminum alloy: a) in the initial state, б) after the micro arc oxidation

$$
-467-
$$


Таблица 2. Фазовый состав образца алюминия после МДО

Table 2. Phase composition of the aluminum sample after MDO

\begin{tabular}{|c|c|c|c|c|c|c|c|c|c|c|c|c|}
\hline № & I, мм & $\begin{array}{c}2 \theta, \\
\text { град }\end{array}$ & $\theta$, град & $\operatorname{Sin} \theta$ & $\mathrm{d} / \mathrm{n}, \mathrm{A}$ & $\mathrm{I}, \%$ & $\mathrm{~d} / \mathrm{n}, \mathrm{A}$ & $\mathrm{I}, \%$ & $\mathrm{hkl}$ & $\mathrm{d} / \mathrm{n}, \mathrm{A}$ & $\mathrm{I}, \%$ & $\mathrm{hkl}$ \\
\hline 1 & 680 & 38,64 & 19,32 & 0,3308 & 2,330 & 100 & 2,338 & 100,0 & 111 & 2,315 & 45 & 401 \\
\hline 2 & 56 & 44,84 & 22,42 & 0,3814 & 2,021 & 8,0 & 2,024 & 47,0 & 200 & 2,019 & 45 & 112 \\
\hline 3 & 50 & 65,3 & 32,65 & 0,5395 & 1,429 & 7,0 & 1,431 & 22,0 & 220 & 1,426 & 10 & 710 \\
\hline 4 & 11 & 78,42 & 39,21 & 0,6322 & 1,219 & 2,0 & 1,221 & 24,0 & 311 & & & \\
\hline 5 & 10 & 82,58 & 41,29 & 0,6599 & 1,168 & 1 & 1,169 & 7 & 222 & & & \\
\hline 6 & 7 & 112,2 & 56,1 & 0,8300 & 0,929 & 1 & 0,929 & 8 & 331 & & & \\
\hline 7 & 7 & 116,62 & 58,31 & 0,8509 & 0,906 & 1 & 0,905 & 8,0 & 420 & & & \\
\hline
\end{tabular}

Таблица 3. Результаты микротвердости после МДО

Table 3. Microhardness results after MDO

\begin{tabular}{|c|c|c|c|c|c|c|c|c|c|c|c|c|c|}
\hline № & $\mathrm{z1}$ & $\mathrm{z} 3$ & $\mathrm{z} 2$ & $\mathrm{z} 4$ & $\mathrm{zr}$ & $\mathrm{zb}$ & $\mathrm{z}$ & $\mathrm{d}$ & H,MПа & L,мкм & Нср & Нср-Н & $(\text { Нср-Н })^{\wedge} 2$ \\
\hline 1 & 250 & 408 & 172 & 325 & 158 & 153 & 155,5 & 34,21 & 777,56 & 0 & $\mathbf{7 4 6}$ & $-32,06$ & 1027,89 \\
\hline 2 & 250 & 411 & 160 & 320 & 161 & 160 & 160,5 & 35,31 & 729,87 & 100 & $\mathbf{7 4 6}$ & 15,63 & 244,33 \\
\hline 3 & 250 & 412 & 161 & 320 & 162 & 159 & 160,5 & 35,31 & 729,87 & 200 & $\mathbf{7 4 6}$ & 15,63 & 244,33 \\
\hline 4 & 250 & 407 & 164 & 322 & 157 & 158 & 157,5 & 34,65 & 757,94 & 300 & $\mathbf{7 4 6}$ & $-12,44$ & 154,71 \\
\hline 5 & 250 & 405 & 163 & 325 & 155 & 162 & 158,5 & 34,87 & 748,41 & 400 & $\mathbf{7 4 6}$ & $-2,90$ & 8,44 \\
\hline 6 & 250 & 407 & 160 & 324 & 157 & 164 & 160,5 & 35,31 & 729,87 & 500 & $\mathbf{7 4 6}$ & 15,63 & 244,33 \\
\hline 7 & 250 & 410 & 160 & 323 & 160 & 163 & 161,5 & 35,53 & 720,86 & 600 & $\mathbf{7 4 6}$ & 24,64 & 607,21 \\
\hline 8 & 250 & 410 & 163 & 320 & 160 & 157 & 158,5 & 34,87 & 748,41 & 700 & $\mathbf{7 4 6}$ & $-2,90$ & 8,44 \\
\hline 9 & 250 & 409 & 164 & 318 & 159 & 154 & 156,5 & 34,43 & 767,66 & 800 & $\mathbf{7 4 6}$ & $-22,16$ & 490,87 \\
\hline 10 & 250 & 408 & 164 & 322 & 158 & 158 & 158 & 34,76 & 753,15 & 900 & $\mathbf{7 4 6}$ & $-7,65$ & 58,51 \\
\hline 11 & 250 & 411 & 164 & 322 & 161 & 158 & 159,5 & 35,09 & 739,05 & 1000 & $\mathbf{7 4 6}$ & 6,45 & 41,61 \\
\hline 12 & 250 & 410 & 163 & 321 & 160 & 158 & 159 & 34,98 & 743,71 & 1100 & $\mathbf{7 4 6}$ & 1,79 & 3,22 \\
\hline 13 & 250 & 407 & 161 & 320 & 157 & 159 & 158 & 34,76 & 753,15 & 1200 & $\mathbf{7 4 6}$ & $-7,65$ & 58,51 \\
\hline 14 & 250 & 409 & 162 & 324 & 159 & 162 & 160,5 & 35,31 & 729,87 & 1300 & $\mathbf{7 4 6}$ & 15,63 & 244,33 \\
\hline 15 & 250 & 408 & 163 & 321 & 158 & 158 & 158 & 34,76 & 753,15 & 1400 & $\mathbf{7 4 6}$ & $-7,65$ & 58,51 \\
\hline
\end{tabular}

Это может быть обусловлено тем, что при обработке от высокой температуры плазмы возникает внутреннее напряжение. Источниками напряжений являются: градиенты температур по сечению; неоднородность химического состава; структурные несовершенства; разная ориентировка кристаллов в пространстве; различный удельный объем и различные коэффициенты линейного расширения фаз [19].

Микротвердость возросла на всех режимах обработки микродугового оксидирования сплава алюминия. Средняя микротвердость, достигнутая при микродуговом оксидировании, составляет 746 МПа (табл. 3), что примерно в 2,5 раза выше, чем у исходного материала (рис. 7). 


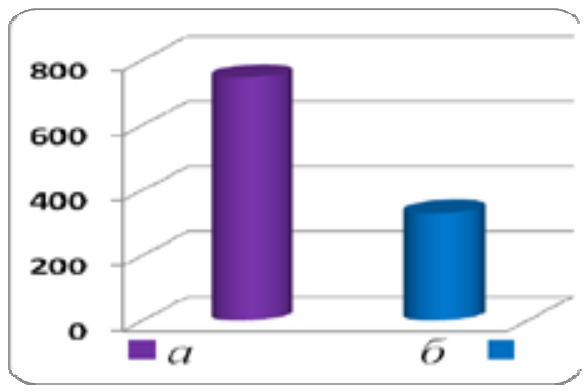

Рис. 7. Среднее значение микротвердости: а - после МДО, б - в исходном состоянии

Fig. 7. The average value of micro hardness: $a-$ after mao, $\sigma-$ in the initial state

После микродугового оксидирования наблюдается повышение значений микротвердости (рис. 7a) относительно исходного состояния (рис. 7б), что, безусловно, повышает эксплуатационные качества деталей из алюминиевого сплава.

\section{Выводы}

Для упрочнения алюминиевого сплава вместо традиционной термической обработки предложена альтернативная технология электролитно-плазменного упрочнения. Образцы из алюминиевого сплава АЛ3 ГОСТ2685-75 подвергались циклическому нагреву от температуры микроплазмы и закаливались в потоке электролита. Нагрев до температуры структурно-фазовых превращений происходит при значительно низких энергозатратах по сравнению с традиционной термообработкой. Экспериментально установили оптимальные режимы микродугового оксидирования алюминия: напряжение источника питания $\mathrm{U}=200 \mathrm{~B}$, сила тока $\mathrm{I}=10 \mathrm{~A}$, время нагрева $\mathrm{t}=2 \mathrm{c}$, время закалки $\mathrm{t}=24 \mathrm{c}$, общее количество циклов $\mathrm{n}=15$. Предварительно установили зависимость температуры нагрева от времени нагрева, охлаждения и напряжения, которая выражена формулой: $\mathrm{T}=4.5 \mathrm{xt}^{2}$ наг. $+4.8 \mathrm{xU}-18 \mathrm{xt}_{\text {охл }}$. После микродугового оксидирования наблюдается микроструктура закалки и искусственного старения в потоке электролита. В результате закалки твердый $\alpha$-раствор меди в алюминии и точечные мелкодисперсные включения растворяются от температуры микроплазмы, эти фазы, окисляясь, образуют корунд алюминия. Рентгеноструктурный анализ образцов после электролитно-плазменной обработки выявил увеличение интенсивности и уширение дифракционных линий относительно исходного состояния, что свидетельствует об остаточном напряжении поверхности, которая в процессе эксплуатации обеспечивает повышение износостойкости детали. Средняя микротвердость после электролитно-плазменной обработки составляет 746 МПа, что примерно в 2,5 раза выше, чем у исходного материала.

\section{Список литературы}

[1] Pogrebnjak A.D., Kylyhkanov M.K., Gritsenko B.P., Duvanov S.M., Pogrebnjak N.A., Ponaryadov V.V. Technical Physics Letters, Moscow, 2006, 32(12). 1060-1063.

[2] Новиков. А.Н., Кузнецов Ю.А., Хромов В.Н. Устройство для микродугового оксидирования колодцев корпуса шестеренного насоса. Патент RU2147324C1 [Novikov AN,

$$
-469-
$$


Kuznetsov Yu.A., Khromov V.N. Device for micro - oxidation of columns of cores in a gear pumps. Patent RU2147324C1. (in Russian)]

[3] Комбаев К.К., Кылышканов М.К., Лопухов Ю.И. Влияние электролитно-плазменной обработки стали 18ХН3МА-Ш на поверхностную микроструктуру и твердость. Журнал Сибирского федерального университета, серия «Техника и технологии», 2009, 2(4), 394-399 [Kombaev K.K., Kylyshkanov M.K., Lopuhov Yu.I. Electrolyte-plasma treatment of 18XH3MA-Ш on superficial microextructure and thermostability. Journal of the Siberian Federal University, Series Technics and Technologies, 2009, 2(4), 394-399 (in Russian)]

[4] Комбаев К.К., Смагулов Д.У., Кылышканов М.К. Структурно-фазовые превращения в стали 18ХНЗМА-Ш при электролитно-плазменной обработке. Вестник КазНТУ им. К.И. Сатпаева, 2010. 3(79), 199-206 [Kombaev K.K., Smagulov D.U., Kylyshkanov M.K. Structuralphase transformations in steel 18XH3MA-Ш at electrolytic-plasma processing. Vestnik KazNTU im. K.I. Satpayev, 2010, 3 (79), 199-206 (in Russian)]

[5] Тюрин Ю.Н., Погребняк А.Д. Электрическое нагревание с использованием жидкого электрода. Технология поверхности и покрытия, 142-144 (2001), 293-299 [Tyurin Y.N., Pogrebnjak A.D. Electric heating using a liquid electrode. Surface and Coatings Technology, 142-144 (2001), 293-299 (in Russian)]

[6] Кылышканов М.К., Комбаев К.К. Методы поверхностного упрочнения чугуна на основе электролитно-плазменной обработки. Вестник ВКГТУ. Усть-Каменогорск, 2008, 3, 46-49 [Kilyshkanov M.K., Kombaev K.K. Methods of surface hardening of cast iron based on electrolyticplasma treatment. Vestnik EKSTU. Ust-Kamenogorsk, 2008, 3, 46-49. (in Russian)]

[7] Кылышканов М.К., Комбаев К.К. Методы поверхностного упрочнения деталей на основе электролитно-плазменной обработки. Вестник ВКГТУ. Усть-Каменогорск, 2008. 4, 5961 [Kylishkanov M.K., Kombaev K.K. Methods of surface hardening of parts based on electrolyticplasma treatment. Vestnik EKSTU. Ust-Kamenogorsk, 2008, 4, 59-61 (in Russian)]

[8] Комбаев К.К., Кылышканов М.К. Влияние режимов электролитно-плазменной закалки на структуру и свойства стали бурового долота. Труды КарГТУ. Караганда, 2009, 2, $16-$ 18 [Kombaev K.K., Kylyshkanov M.K. Influence of electrolytic-plasma quenching regimes on the structure and properties of the steel of a drill bit, Proceedings of KSTU. Karaganda, 2009, 2, 16-18 (in Russian)]

[9] Комбаев К.К., Кылышканов М.К., Скаков М.К. Исследование влияния электролитноплазменной обработки на структуру и износостойкость стали бурового инструмента. Вестник КазНТУ. Алматы, 2010, 1(77), 105-111 [Kombaev K.K., Kylyshkanov M.K., Skakov M.K. Investigation of the effect of electrolyte-plasma treatment on the structure and wear resistance of the steel of the drilling tool. Bulletin of KazNTU. Almaty, 2010, 1 (77), 105-111 (in Russian)]

[10] Комбаев К.К., Кылышканов М.К., Лопухов Ю.И. Исследование свойств модификации поверхности после электролитно-плазменной обработки стали 18ХН3МА-Ш. Вестник Наџиональной инженерной академии Республики Казахстан. Алматы, 2009, 2(32), 142-146 [Kombaev K.K., Kylyshkanov M.K., Lopukhov Yu.I. Investigation of surface modification properties after electrolytic-plasma treatment of steel 18XH3MA-Ш. Bulletin of the National Engineering Academy of the Republic of Kazakhstan. Almaty, 2009, 2 (32), 142-146 (in Russian)] 
[11] Кожа Е., Комбаев К.К., Смагулов Д.У. Элктролитті - плазмалық өңдеу кезіндегі азкөміртекті легірленген болаттағы құрылымдық фазалық өзгеру. Вестник КазНТУ им. К.И. Сатпаева. Алматы, 2014, 3(103), 300-307 [Kozha E., Kombayev K.K., Smagulov D.U. Structural phase transformation of low-carbon steel alloy with elcrolyte-plasma treatment. Bylletin of KazTTY K.I. Satpaeva. Almaty, 2014., 3 (103), 300-307]

[12] Еркин К., Смагулов Д.У., Комбаев Қ. Электролитті-плазмалық өңдеуден кейінгі болаттың беткі қабатының құрылысы мен қасиеттерінің өзгеруі. Қазақстан-Британ Техникальқ университетінің хабаршысы Алматы, 2017, 2-3(41-42), 101-105. [Erkin К., Smagulov D.U., Kombaev K. Changes in the structure and properties of steel surface surface after electrolyte-plasma treatment . Bulletin of the Kazakh-British Technical University Almaty. 2017, 2-3 (41-42), 101-105]

[13] Комбаев К.К., Смагулов Д.У., Кожа Е., Ахметова Г.Е. Лабораторная установка для электролитно-плазменной обработки стали. Нанотехнологии наука и производство, 2016, 4, 4955 [Kombaev K.K., Smagulov D.U., Skin E., Akhmetova G.E. Laboratory installation for electrolyticplasma processing of steel. Nanotechnology science and production, 2016, 4, 49-55 (in Russian)]

[14] Тюленин А.Н., Тюрин Ю.Н., Граднев А.И. Гистерезис вольтамперных характеристик источников питания. МИТОМ., М., 1988, 1, 9-12 [Tyulenin A.N., Tyurin Yu.N., Gradnev A.I. Hysteresis of volt-ampere characteristics of power supplies, MITOM. M., 1988, 1, 9-12 (in Russian)]

[15] Комбаев К.К., Скаков М.К., Путренко Н.Ф. Заключение о выдаче патента на полезную модель «Стенд для испытания материалов на трение и износ». МПК G01N 3/56 (2009.01) [Kombaev K.K., Skakov M.K., Putrenko N.F. Conclusion on the grant of a patent for the utility model «Bench for testing materials for friction and wear». IPC G01N 3/56 (2009.1) (in Russian)]

[16] Кылышканов М.К., Комбаев К.К., Погребняк А.Д. Пат. 23178 РК. Способ электролитноплазменного упрочнения деталей бурового долота. Дата подачи 06.05.2009г., зарегистрировано 20.09.2010 г., МПК C21D1/78 (2009.01), C21D 1/34 (2009.01) [Kylyshkanov M.K., Kombaev K.K., Pogrebnyak A.D. Pat. 23178 PK. Method of electrolytic-plasma hardening of drill bit parts. filing date 06.05.2009, registered on September 20, 2010, IPC C21D1/78 (2009.01), C21D 1/34 (2009.01) (in Russian)]

[17] Комбаев К.К., Кожа Е., Смагулов Д.Ю. и Саде Б. Структурные фазовые переходы низкоуглеродистых сплавов при электролитно-плазменной обработке. 2016, 2-я Международная конференция по искусственному и промышленному проектированию. Beiging, China, 2016. Part 2. C. 491-495 [Kombaev K.K., Kozha E., Smagulov D.U. and Sadeh B. Structural Phase Transitions of Low-Carbon Alloy Steels during Electrolitic-Plasma Processing. $20162^{\text {nd }}$ International Conference on Artificial and Industrial Engineering. Beiging, China, 2016. Part 2. 491-495 (in Russian)]

[18] Кожа Е., Смагулов Д.Ю., Ахметова Г.Е., Комбаев К.К. Лабораторная установка для электролитической плазменной обработки стали. Известия Национальной академии наук Республики Казахстан. Алматы, nas rk, 2017, 4 (424), 219-225 [Kozha E., Smagulov D.U., Akhmetova G.E., Kombaev K.K. Laboratory installation for electrolytic-plasma treatment of steel. News of national academy of sciences of the republic of Kazakhstan. Almaty, nas rk, 2017, 4(424), 219-225 (in Russian)]

$$
-471-
$$


[19] Комбаев К.К. Разработка технологии электролитно-плазменной обработки низкоуглеродистой легированной стали бурового инструмента. Монография, Алматы «Эверо», 2015. 92 с.:ил. [Kombaev K.K. Development of technology of electrolytic-plasma treatment of low-carbon alloyed steel of the drilling tool. Monograph, Almaty "Evero", 2015. 92 p. (in Russian)] 